\title{
Maternal anthropometric and metabolic factors in the first half of pregnancy and risk of neonatal macrosomia in term pregnancies. A prospective study
}

\author{
T Clausen, T K Burski ${ }^{1}$, N Øyen ${ }^{2}$, K Godang $^{1}$, J Bollerslev ${ }^{1}$ and T Henriksen ${ }^{3}$ \\ Woman and Child Division, Ullevål University Hospital, ${ }^{1}$ Department of Endocrinology, Rikshospitalet University Hospital, ${ }^{2}$ Department of Public Health \\ and Primary Health Care, University of Bergen, 5025 bergen, Norway and ${ }^{3}$ Department of Obstetrics and Gynecology, Rikshospitalet University \\ Hospital, O027 Oslo, Norway
}

(Correspondence should be addressed to T Henriksen; Email: tore.henriksen@rikshospitalet.no)

\begin{abstract}
Objective: The prevalence of maternal overweight and fetal macrosomia is increasing. Fetal macrosomia is associated with increased risk of maternal and neonatal complications. The objective of the present study was to investigate if maternal metabolic parameters associated with maternal overweight were independent determinants of macrosomia (birth weight $>4500 \mathrm{~g}$ or above the 95 percentile of the z-score for standardized birth weight).

Design: Prospective population based cohort study of 2050 pregnancies and nested case control study. Methods: Outcome measures were adjusted risks for macrosomia in relation to early second trimester maternal serum lipids, glucose and insulin (cohort study) and leptin and insulin-like growth factor (73 cases and 146 matched controls).

Results: Gestational diabetes was not independently associated with fetal macrosomia. First trimester body mass index (BMI), gestational weight gain and placental weight were associated with macrosomia. High serum insulin and non-high density lipoprotein (HDL)-cholesterol and low serum HDL-cholesterol were associated with increased risk of macrosomia independent of BMI, weight gain, placental weight and gestational diabetes. Slim women with macrosomic infants had higher insulin compared with those with normal weight infants. This relation was not found among obese women. Leptin was not associated with macrosomia after adjusting for maternal BMI.

Conclusions: Blood parameters known to be associated with the metabolic syndrome were risk factors for macrosomia independent of maternal BMI.
\end{abstract}

European Journal of Endocrinology 153 887-894

\section{Introduction}

Large size infants have become more prevalent in affluent societies during the last decades. Pregnancies with macrosomic infants are associated with increased risk of complications for both the baby and its mother, such as intrauterine death, artificial induction of labor, prolonged birth, birth asphyxia, injuries to the baby and the mother, increased use of operative deliveries, post partum hemorrhages and neonatal hypoglycemia, hyperbilirubinemia and the use of neonatal intensive care (1-3). In addition, oversized infants may suffer long term effects because of increased risks of neurological sequels, adiposity, diabetes and cancer (4-8). The causes of the increasing prevalence of large newborns are complex and insufficiently explained.

Maternal anthropometric parameters, such as pregestational body size indices and gestational weight gain have repeatedly been shown to be independent determinants of the size of the offspring (9-12). The increasing prevalence of being overweight among young women as well as the decline in smoking, is currently considered a major cause of large infants in the population (13). Overweight is, however, associated with complex changes in metabolic and endocrine parameters, changes that may differ among subgroups of obese individuals (14). Therefore, maternal metabolic and endocrine factors may well be independent determinants of fetal growth. Glucose intolerance in pregnancy, including gestational diabetes, has traditionally been considered a determinant of accelerated fetal growth independent of maternal size, although the evidence cannot be considered conclusive on a general basis $(15-17)$. With overweight there also follows changes in lipid metabolism and a variety of accompanying hormonal alterations (14). Apart from maternal plasma glucose, studies on the role of maternal 
metabolic parameters as independent determinants of fetal growth are limited $(18,19)$.

The purpose of the present study was to investigate prospectively if maternal metabolic parameters associated with maternal weight were independent determinants of large baby size at term.

\section{Materials and methods}

\section{Prospective cohort study}

This study was part of a large prospective cohort study performed at Aker Hospital in 1995-1996, conducted to assess risk factors for the development of preeclampsia (20). Aker was at that time a university hospital with all levels of obstetric care. The hospital covered defined geographical areas of Oslo city, representing all socio-economic classes. Approximately $95 \%$ of the pregnant women in these areas gave birth at this hospital. The transfer of women to other hospitals because of medical reasons was exceptional $(<0.5 \%)$.

All pregnant women in the areas were offered an ultrasound investigation at 17-19 weeks of gestation. In a period of 21 months in 1995-1996, women of Norwegian ancestry who received the offer of ultrasound screening were simultaneously asked to provide a blood sample. Women with pre-gestational diabetes were not included. Blood samples from 2434 women were obtained, i.e. from $93.4 \%$ of the recruited women. Women with multiple pregnancies $(n=28)$ and preterm births (before 37 completed weeks) $(n=100)$ were excluded from the present study. Seven women were excluded because the medical records were missing and 5 women because information on birth weight was unavailable. Two hundred and forty-four women were lost for follow-up mainly because they moved out of the area. Thus the study population consisted of 2050 pregnant women.

Maternal anthropometry and medical status (age, parity, smoking, first trimester weight, height, gestational weight gain, blood pressures) and pregnancy outcome (preeclampsia, gestational diabetes, birth weight, birth length, gestational age, gender of the baby, placental weight) were retrieved from medical records after delivery by Torun Clawsen. The diagnosis of gestational diabetes was based on an oral fasting glucose tolerance test (OGTT, serum glucose $>7.8 \mathrm{mmol} / \mathrm{l}$ $2 \mathrm{~h}$ after $75 \mathrm{~g}$ glucose). In Norway, OGTT is performed at 28 weeks of gestation in women at risk for diabetes mellitus (glucosuria, previous gestational diabetes, previous fetal macrosomia (birth weight $>4500 \mathrm{~g}$ ), previous perinatal death, maternal overweight (body mass index (BMI) $>27 \mathrm{~kg} / \mathrm{m}^{2}$ ), diabetes mellitus in close family). The diagnosis of preeclampsia was based on the presence of proteinuria and pregnancy-induced hypertension. Proteinuria was defined by two readings of $\geq+1$ on a dipstick $(300 \mathrm{mg} / 24 \mathrm{~h})$ with an interval of $\geq 6 \mathrm{~h}$ between the tests. Pregnancy-induced hypertension was defined either as blood pressure $\geq 140 / 90 \mathrm{mmHg}$ or as an increase in diastolic pressure of $\geq 15 \mathrm{mmHg}$ compared with average measurements before 20 weeks of gestation. In both cases two measurements taken $\geq 6 \mathrm{~h}$ apart were required.

We defined macrosomia as birth weight above $4500 \mathrm{~g}$ or a z-score above the 95 percentile (see Statistical analysis below).

\section{Nested matched case control study among women with term pregnancies and without diabetes or preeclampsia}

Seventy-three women from the study population who gave birth to a baby with a birth weight above $4500 \mathrm{~g}$ at term and without gestational diabetes or preeclampsia had frozen blood samples eligible for leptin and insulin-like growth factor-I (IGF-I) analyses. The controls $(n=146)$ were pregnant women from the study population without gestational diabetes or preeclampsia and who delivered a baby with a birth weight of 3000 to $\leq 4000 \mathrm{~g}$. For each case, two controls matched for age, parity and gestational age were selected within the study population.

\section{Blood samples}

Blood samples were drawn in the non-fasting state. The blood samples were allowed to coagulate before centrifugation at $400 \boldsymbol{g}$ for $10 \mathrm{~min}$. The serum samples were transferred on ice to a $\left(70{ }^{\circ} \mathrm{C}\right.$ freezer within $140 \mathrm{~min}$. Routine serum chemistries were performed by staff at Aker University Hospital for all women in the cohort at the time of collection, to determine serum lipids (triglycerides, total cholesterol, high density lipoprotein (HDL)-cholesterol, non-HDL-cholesterol) and glucose concentrations. Serum insulin was assayed by RIA with a kit from DPC (Los Angeles, CA, USA). The concentration of leptin was assayed with a kit from Linco Research Inc. (St Charles, MO, USA). Serum levels of IGF-I were analyzed by IRMA (Nichols Institute, Nijmegen, The Netherlands). The intra- and interassay coefficients of variation were $<11 \%$ for all assays.

The study was approved by the Regional Medical Ethics Committee and written informed consent was obtained from the participants.

\section{Statistical analysis}

For data analysis we used the statistical program 11.0 SPSS for Windows (SPSS Inc, Chicago, IL, USA).

Birth weight was dichotomized as $\leq 4500 \mathrm{~g}$ and $>4500$ g. Since gestational age was significantly longer among infants $>4500 \mathrm{~g}$ than infants $\leq 4500 \mathrm{~g}$, we standardized birth weights within weeks of gestational age and by gender of the offspring. Standardized birth weights were based on data from the Medical Birth Registry of Norway (21), and were 
calculated as z-scores by subtracting the calculated mean of the reference population from the observed value and dividing by the S.D. We defined macrosomia as the z-score above the 95 percentile. The 2-sample $t$ test or the non-parametric Mann-Whitney test was used to compare continuous variables between women with macrosomic and normal weight babies. Proportions were compared using the $\chi^{2}$ test. Correlations were estimated by Pearson correlation coefficient. Relative risks were evaluated by logistic regression analyses. We used the odds ratio $(\mathrm{OR})$ to approximate relative risk. In all regression analyses, covariates were represented by indicator variables to allow for non-linear dose-response relationships. BMI was defined as $\mathrm{kg} / \mathrm{m}^{2}$. The women were classified according to first trimester BMI as lean ( $\leq 20$ ), normal weight ( 20 to $\leq 25$ ), overweight ( 25 to $\leq 30)$, and obese $(>30)$. For maternal age we used the categorization $\leq 25,25$ to $\leq 30,30$ to $\leq 35$ and $>35$ years. Maternal first trimester weight, height, weight gain, placental weight and the blood sample variables were categorized according to quartiles of their distributions. For variables with a high number of missing values (above 30) those cases were included in the analysis as a separate category. Tests for linear trends were used to assess graded associations (missing category excluded).

In the nested case control part of the study, OR for birth weight above $4500 \mathrm{~g}$ was evaluated by use of conditional logistic regression analysis. Stratified Cox regression models were used to fit the conditional logistic regression model, because these two models give the same likelihood function and thus the same estimates (22). Also, in these regression analyses the covariates were represented by indicator variables to allow for non-linear relationships. $P<0.05$ was considered significant.

\section{Results}

\section{Cohort study}

Background characteristics are presented in Table 1. Eighty-eight $(4.3 \%)$ of the 2050 women in the cohort gave birth to a baby with a birth weight above $4500 \mathrm{~g}$, whereas 104 women had a z-score for birth weight above the 95 percentile.

Women who delivered a baby with a birth weight above $4500 \mathrm{~g}$ were taller, had a higher first trimester weight, higher first trimester BMI, higher weight gain during pregnancy and higher placental weight than women who delivered a baby of $4500 \mathrm{~g}$ or less. Gestational diabetes was more frequent among women delivering a baby with a birth weight above $4500 \mathrm{~g}$ than in women giving birth to a baby with a lower birth weight $\quad(5.7 \%$ compared with $1.9 \%, \quad P<0.05)$. Early second trimester serum concentrations of insulin, glucose, triglycerides and non-HDL-cholesterol were higher and HDL-cholesterol was lower in women delivering babies of high birth weight (Table 1). Using

Table 1 Cohort study. Characteristics, pregnancy outcomes and blood parameters at 18 weeks of gestation in 2050 pregnant women. Results for age, blood pressure, height and weight parameters are expressed as mean (S.D.), these for category variables as $n$ (\%) and those for blood parameters as median (25-75 percentile).

\begin{tabular}{|c|c|c|c|}
\hline & All $(n=2050)$ & Birth weight $\leq 4500 \mathrm{~g}(n=1962)$ & Birth weight $>4500 \mathrm{~g}(n=88)$ \\
\hline Age (years) & $29.9(4.4)$ & $29.9(4.5)$ & $30.6(4.2)$ \\
\hline Systolic BP Ist trimester $(\mathrm{mmHg})$ & $112.7(10.4)$ & $112.7(10.3)$ & $112.2(11.4)$ \\
\hline Diastolic BP Ist trimester $(\mathrm{mmHg})$ & $67.9(7.8)$ & $67.9(7.8)$ & $69.0(7.9)$ \\
\hline Systolic BP at delivery $(\mathrm{mmHg})$ & $117.8(11.9)$ & $117.7(11.9)$ & $119.2(12.0)$ \\
\hline Diastolic BP at delivery $(\mathrm{mmHg})$ & $74.2(9.5)$ & $74.2(9.5)$ & $75.9(9.0)$ \\
\hline Maternal height $(\mathrm{cm})$ & $168.3(5.7)$ & $168.1(5.7)$ & $171.0(5.7)^{\star \star \star}$ \\
\hline Maternal weight Ist trimester $(\mathrm{kg})$ & $65.0(11.2)$ & $64.7(11.0)$ & $72.2(13.9)^{\star \star *}$ \\
\hline Maternal BMI Ist trimester $\left(\mathrm{kg} / \mathrm{m}^{2}\right)$ & $23.0(3.7)$ & $22.9(3.7)$ & $24.8(4.3)^{\star \star * \star}$ \\
\hline Weight gain $(\mathrm{kg})$ & $15.4(9.7)$ & $15.3(9.8)$ & $18.2(5.7)^{\star \star}$ \\
\hline Placental weight $(\mathrm{g})$ & $667.8(144.3)$ & $659.7(138.8)$ & $845.5(149.1)^{\star \star *}$ \\
\hline Gestational age (weeks) & $39.7(1.3)$ & $39.7(1.3)$ & $40.5(1.1)^{\star \star \star}$ \\
\hline Birth weight $(\mathrm{g})$ & $3637.9(39.7)$ & $3589(443)$ & $4739(218)^{\star \star \star}$ \\
\hline Nullipara & $n=1030(50.3)$ & $n=1000(51.0)$ & $n=30(34.1)^{\star *}$ \\
\hline Smoking & $n=440(22.2)$ & $n=425$ & $n=15(17.0)$ \\
\hline Preeclampsia & $n=53(2.6)$ & $n=50(2.5)$ & $n=3(3.4)$ \\
\hline Gestational diabetes & $n=42(2.1)$ & $n=37(1.9)$ & $n=5(5.7)^{*}$ \\
\hline Male offspring & $n=1066(52.1)$ & $n=999(51.0)$ & $n=67(76.1)^{* * *}$ \\
\hline Insulin (pmol/l) & $80.0(39.0-154.0)$ & $79.0(38.0-150.0)$ & $126.0(61.0-234.5)^{\star \star *}$ \\
\hline Glucose $(\mathrm{mmol} / \mathrm{l})$ & $4.1(3.8-4.6)$ & $4.1(3.8-4.6)$ & $4.4(3.8-5.1)^{\star *}$ \\
\hline Triglycerides $(\mathrm{mmol} / \mathrm{l})$ & $1.5(1.2-1.9)$ & $1.5(1.2-1.9)$ & $1.7(1.4-2.1)^{\star *}$ \\
\hline Total cholesterol $(\mathrm{mmol} / \mathrm{l})$ & $5.3(4.8-5.9)$ & $5.3(4.8-5.9)$ & $5.5(4.8-6.0)$ \\
\hline HDL-cholesterol (mmol/l) & $1.8(1.5-2.0)$ & $1.8(1.5-2.0)$ & $1.6(1.4-1.9)^{*}$ \\
\hline LDL-cholesterol ( $\mathrm{mmol} / \mathrm{l})$ & $2.8(2.3-3.3)$ & $2.8(2.3-3.3)$ & $3.0(2.4-3.6)^{\star}$ \\
\hline
\end{tabular}

${ }^{\star} P<0.05,{ }^{* \star} P<0.001,{ }^{* \star \star} P<0.001$ (Student's $t$-test or Mann-Whitney test (blood parameters) for continuous variables and $\chi^{2}$-test for categorical variables). BP, blood pressure; HDL, high density lipoprotein; LDL, low density lipoprotein. 
standardized birth weights gave similar findings as absolute birth weight (data not shown).

There was a positive correlation in the cohort between first trimester BMI and concentrations of insulin $(r=0.23, P<0.001)$, glucose $(r=0.21, P<0.001)$, triglycerides $(r=0.26, \quad P<0.001)$, total cholesterol $(r=0.08, P<0.001)$ and non-HDL-cholesterol $(r=0.11, P<0.001)$, and an inverse correlation between BMI and HDL-cholesterol $(r=(0.21$, $P<0.001)$. Body mass index was also correlated to placental weight $(r=0.12, P<0.001)$ and to gestational weight gain $(r=(0.09, P<0.001)$.

Among lean women $(\mathrm{BMI} \leq 20)$ insulin and glucose concentrations were higher for women who delivered macrosomic babies (birth weight above $4500 \mathrm{~g}$ ) compared with those who had non-macrosomic infants (Table 2). In contrast, there were no differences in insulin and glucose levels among obese women (BMI > 30) who had normal weight and high weight babies $(>4500 \mathrm{~g})$. Similar results were obtained when macrosomia was defined as a z-score for birth weight above the 95 percentile (data not shown). Maternal weight gain was also higher at all BMI levels except for those women with BMI above 30. Placental weight was higher at all BMI levels for women delivering macrosomic $(>4500 \mathrm{~g})$ infants compared with those with non-macrosomic infants.

By univariate logistic regression analyses, we found that first trimester BMI, maternal weight gain, gestational diabetes, placental weight, insulin, glucose, triglycerides, HDL-cholesterol and non-HDL-cholesterol were positively associated with risk of macrosomia (birth weight $>4500 \mathrm{~g}$ ) (Table 3). Multiple logistic regression analyses (blood parameters not included) showed that first trimester maternal BMI, maternal weight gain and placental weight were independent risk factors for macrosomia (both defined as birth weight $>4500 \mathrm{~g}$ at term and z-scores $>$ the 95 percentile) (Table 3, data for z-score not shown). After including each blood parameter separately into the model, the effect of BMI remained essentially unchanged (data not shown). High levels of insulin and non-HDL-cholesterol and low levels of HDL-cholesterol were associated with increased risk of high birth weight independent of maternal BMI, weight gain, placental weight and gestational diabetes (Table 3).

\section{Nested case control study}

There was no difference in age, gestational age and parity between cases and controls (matched parameters) (Table 4). Maternal weight gain and placental weight were higher among cases compared with controls. The proportion of smokers was lower, whereas the proportion of male infants was higher among the cases.

As in the cohort study, we found that serum insulin, triglycerides and non-HDL-cholesterol was higher and that HDL-cholesterol was lower in women with high birth weight babies. In this part of the study, we found no statistically significant difference in glucose levels between cases and controls (data not shown). The serum levels of lipids, insulin and glucose in women giving birth to babies with a birth weight above or below $4500 \mathrm{~g}$ were similar in the cohort and the case control study (data not shown).

Women with macrosomic babies had higher second trimester leptin concentrations compared with women with normal weight babies. IGF-I concentrations were similar in the two groups (Table 4).

By conditional univariate logistic regression analyses high levels of leptin were associated with a birth weight above $4500 \mathrm{~g}$. After adjusting for maternal BMI, leptin was not associated with high birth weight (data not shown).

\section{Discussion}

Recent studies have consistently shown that maternal BMI is a strong independent predictor of the birth weight of the offspring $(23-26)$. In the present study, we have prospectively studied markers of maternal metabolism and fetal growth as predictors of large

Table 2 Cohort study. Maternal serum insulin and glucose levels at 18 weeks of gestation in women with different levels of first trimester body mass index (BMI).

\begin{tabular}{|c|c|c|c|c|c|c|}
\hline & & \multicolumn{2}{|c|}{ Birth weight $\leq 4500 \mathrm{~g}$} & \multicolumn{2}{|c|}{ Birth weight $>4500 \mathrm{~g}$} & \multirow[b]{2}{*}{$P$ value† } \\
\hline & & $n$ & Median (25-75 perc) & $n$ & Median (25-75 perc) & \\
\hline \multirow[t]{5}{*}{ Insulin (pmol/l) } & $\mathrm{BMI} \leq 20$ & 306 & $60.0(30.8-117.3)$ & 8 & $154.0(103.8-268.0)$ & 0.005 \\
\hline & $\mathrm{BMI} 20$ to $\leq 25$ & 1118 & $77.0(38.0-148.0)$ & 38 & $97.0(59.0-217.0)$ & 0.026 \\
\hline & BMI 25 to $\leq 30$ & 265 & $100.0(50.0-179.0)$ & 24 & $196.5(70.5-254.5)$ & 0.0013 \\
\hline & $\mathrm{BMI}>30$ & 92 & $126.5(71.5-220.3)$ & 11 & $117.0(54.0-255.0)$ & 0.864 \\
\hline & BMI missing & 133 & 74.0 (38.0-152.5) & 7 & $40.0(33.0-427.0)$ & 0.664 \\
\hline \multirow[t]{5}{*}{ Glucose $(\mathrm{mmol} / \mathrm{l})$} & $\mathrm{BMI} \leq 20$ & 313 & $4.0(3.6-4.3)$ & 8 & $4.6(4.0-5.1)$ & 0.009 \\
\hline & BMI 20 to $\leq 25$ & 1146 & $4.1(3.7-4.6)$ & 38 & $4.1(3.7-4.7)$ & 0.733 \\
\hline & BMI 25 to $\leq 30$ & 269 & $4.3(3.9-4.7)$ & 24 & $4.7(3.8-5.7)$ & 0.043 \\
\hline & $\mathrm{BMI}>30$ & 94 & $4.5(4.0-5.0)$ & 11 & $4.3(4.0-5.1)$ & 0.597 \\
\hline & BMI missing & 137 & $4.1(3.7-4.5)$ & 7 & $4.3(3.7-4.7)$ & 0.622 \\
\hline
\end{tabular}

Perc, percentile; †Mann-Whitney test. 
Table 3 Cohort study. Risk of macrosomia (birth weight above $4500 \mathrm{~g}$ ) in relation to metabolic factors.

\begin{tabular}{|c|c|c|c|c|c|c|c|}
\hline & All & $\begin{array}{c}>4500 \mathrm{~g} \\
n(\%)\end{array}$ & $\begin{array}{c}\text { OR }(95 \% \mathrm{Cl}) \\
\text { unadj }\end{array}$ & $\begin{array}{c}\text { aOR }(95 \% \mathrm{Cl}) \\
\text { Model A } \dagger\end{array}$ & $\begin{array}{c}\text { aOR }(95 \% \mathrm{Cl}) \\
\text { Model B } \neq\end{array}$ & $\begin{array}{c}\text { aOR }(95 \% \mathrm{Cl}) \\
\text { Model C } \S\end{array}$ & $\begin{array}{c}\text { aOR }(95 \% \mathrm{Cl}) \\
\text { Model D\| }\end{array}$ \\
\hline \multicolumn{8}{|c|}{ First trimester body mass index (BMI) } \\
\hline$<20$ & 321 & $8(2.5)$ & 1.0 & & 1.0 & 1.0 & \\
\hline $20-25$ & 1186 & $38(3.2)$ & $1.3(0.6-2.8)$ & & $1.3(0.6-2.8)$ & $0.9(0.4-2.1)$ & \\
\hline $25-30$ & 293 & $24(8.2)$ & $3.5(1.5-7.9)$ & & $3.5(1.5-7.9)$ & $2.5(1.1-6.0)$ & \\
\hline$>30$ & 105 & $11(10.5)$ & $4.6(1.8-11.7)$ & & $4.8(1.9-12.4)$ & $4.3(1.5-12.1)$ & \\
\hline$P$ trend & & & $<0.001$ & & $<0.001$ & $<0.001$ & \\
\hline \multicolumn{8}{|c|}{ Weight gain } \\
\hline Q1 & 474 & $9(1.9)$ & 1.0 & 1.0 & 1.0 & 1.0 & 1.0 \\
\hline Q2 & 495 & $14(2.8)$ & $1.5(0.6-3.5)$ & $1.9(0.8-4.5)$ & $1.5(0.7-3.6)$ & $1.6(0.7-3.8)$ & $2.1(0.8-5.1)$ \\
\hline Q3 & 494 & $26(5.3)$ & $2.9(1.3-6.2)$ & $4.0(1.8-8.8)$ & $2.9(1.3-6.2)$ & $2.5(1.1-5.4)$ & $3.5(1.5-8.0)$ \\
\hline Q4 & 501 & $35(7.0)$ & $3.9(1.8-8.1)$ & $4.9(2.3-10.7)$ & $4.3(2.0-9.1)$ & $3.3(1.5-7.0)$ & $4.3(1.9-9.8)$ \\
\hline$P$ trend & & $<0.001$ & $<0.001$ & $<0.001$ & $<0.001$ & $<0.001$ & $<0.001$ \\
\hline \multicolumn{8}{|c|}{ Gestational diabetes } \\
\hline No & 1995 & $83(4.1)$ & 1.0 & 1.0 & 1.0 & 1.0 & 1.0 \\
\hline Yes & 42 & $5(2.5)$ & $3.1(1.2-8.1)$ & $2.5(0.9-6.6)$ & $2.9(1.1-7.7)$ & $3.2(1.1-9.3)$ & $2.4(0.8-7.2)$ \\
\hline$P$ trend & & & 0.020 & 0.07 & 0.031 & 0.036 & 0.125 \\
\hline \multicolumn{8}{|c|}{ Placental weight } \\
\hline Q1-2 & 1028 & $5(0.5) 1.0$ & 1.0 & 1.0 & 1.0 & 1.0 & \\
\hline Q3 & 494 & $22(4.5)$ & $9.5(3.6-25.3)$ & $9.5(3.5-24.8)$ & $9.0(3.4-24.0)$ & $8.1(3.0-21.5)$ & $7.6(2.8-20.2)$ \\
\hline Q4 & 498 & $61(12.2)$ & $28.6(11.4-71.6)$ & $26.9(10.7-67.5)$ & $27.0(10.8-67.8)$ & $24.8(9.7-61.4)$ & $22.6(8.9-57.1)$ \\
\hline$P$ trend & & & $<0.001$ & $<0.001$ & $<0.001$ & $<0.001$ & $<0.001$ \\
\hline \multicolumn{8}{|l|}{ Insulin } \\
\hline Q1 & 497 & $11(2.2)$ & 1.0 & 1.0 & 1.0 & 1.0 & 1.0 \\
\hline Q2 & 509 & 17 (3.3) & $1.5(0.7-3.3)$ & $1.5(0.7-3.2)$ & $1.5(0.7-3.3)$ & $1.5(0.7-3.4)$ & $1.6(0.7-3.5)$ \\
\hline Q3 & 499 & $22(4.4)$ & $2.0(1.0-4.2)$ & $1.8(0.9-3.8)$ & $2.1(1.0-4.5)$ & $2.2(1.0-4.8)$ & $1.9(0.9-4.2)$ \\
\hline Q4 & 497 & $38(7.6)$ & $3.7(1.8-7.2)$ & $3.1(1.5-6.2)$ & $3.8(1.9-7.6)$ & $4.1(2.0-8.3)$ & $3.4(1.6-7.1)$ \\
\hline$P$ trend & & & $<0.001$ & 0.003 & $<0.001$ & $<0.001$ & $<0.001$ \\
\hline \multicolumn{8}{|l|}{ Glucose } \\
\hline Q1 & 502 & $21(4.2)$ & 1.0 & 1.0 & 1.0 & 1.0 & 1.0 \\
\hline Q2 & 539 & $15(2.8)$ & $0.7(0.3-1.3)$ & $0.6(0.3-1.2)$ & $0.7(0.3-1.3)$ & $0.6(0.3-1.3)$ & $0.6(0.3-1.2)$ \\
\hline Q3 & 461 & $11(2.4)$ & $0.6(0.3-1.2)$ & $0.5(0.2-1.0)$ & $0.5(0.3-1.1)$ & $0.7(0.3-1.4)$ & $0.6(0.3-1.3)$ \\
\hline Q4 & 545 & $41(7.5)$ & $1.9(1.1-3.2)$ & $1.5(0.9-2.6)$ & $1.9(1.1-3.3)$ & $1.9(1.1-3.4)$ & $1.6(0.9-2.9)$ \\
\hline$P$ trend & & & 0.010 & 0.073 & 0.010 & 0.010 & 0.048 \\
\hline \multicolumn{8}{|c|}{ Triglycerides } \\
\hline Q1 & 437 & $10(2.3)$ & 1.0 & 1.0 & 1.0 & 1.0 & 1.0 \\
\hline Q2 & 668 & $28(4.2)$ & $1.9(0.9-3.9)$ & $1.7(0.8-3.6)$ & $1.9(0.9-3.9)$ & $1.6(0.7-3.3)$ & $1.4(0.7-3.1)$ \\
\hline Q3 & 394 & $15(3.8)$ & $1.7(0.8-3.8)$ & $1.4(0.6-3.2)$ & $1.7(0.7-3.8)$ & $1.4(0.6-3.2)$ & $1.3(0.5-2.9)$ \\
\hline Q4 & 551 & $35(6.4)$ & $2.9(1.4-5.9)$ & $2.2(1.1-4.6)$ & $2.9(1.4-5.9)$ & $2.5(1.2-5.2)$ & $1.9(0.9-4.1)$ \\
\hline$P$ trend & & & 0.004 & 0.062 & 0.004 & 0.016 & 0.121 \\
\hline \multicolumn{8}{|c|}{ Total cholesterol } \\
\hline Q1 & 497 & $20(4.0)$ & 1.0 & 1.0 & 1.0 & 1.0 & 1.0 \\
\hline Q2 & 565 & 19 (3.4) & $0.8(0.4-1.6)$ & $0.8(0.4-1.5)$ & $0.8(0.4-1.6)$ & $0.7(0.4-1.4)$ & $0.7(0.3-1.3)$ \\
\hline Q3 & 448 & $25(5.6)$ & $1.4(0.8-2.6)$ & $1.4(0.7-2.5)$ & $1.4(0.8-2.5)$ & $1.3(0.7-2.4)$ & $1.4(0.7-2.6)$ \\
\hline Q4 & 540 & $24(4.4)$ & $1.1(0.6-2.0)$ & $1.0(0.5-1.8)$ & $1.1(0.6-2.0)$ & $0.9(0.5-1.7)$ & $0.9(0.5-1.7)$ \\
\hline$P$ trend & & & 0.397 & 0.610 & 0.451 & 0.751 & 0.737 \\
\hline \multicolumn{8}{|c|}{ High density lipoprotein cholesterol } \\
\hline Q1 & 509 & $38(7.5)$ & 1.0 & 1.0 & 1.0 & 1.0 & 1.0 \\
\hline Q2 & 498 & $18(3.6)$ & $0.5(0.3-0.8)$ & $0.5(0.3-0.9)$ & $0.5(0.3-0.8)$ & $0.5(0.3-0.9)$ & $0.6(0.3-1.0)$ \\
\hline Q3 & 527 & 18 (3.4) & $0.4(0.2-0.8)$ & $0.5(0.3-1.0)$ & $0.4(0.2-0.7)$ & $0.5(0.2-0.8)$ & $0.5(0.3-1.0)$ \\
\hline Q4 & 516 & $14(2.7)$ & $0.3(0.2-0.6)$ & $0.4(0.2-0.8)$ & $0.3(0.2-0.6)$ & $0.4(0.2-0.7)$ & $0.4(0.2-0.8)$ \\
\hline$P$ trend & & & $<0.001$ & 0.008 & $<0.001$ & 0.001 & 0.009 \\
\hline \multicolumn{8}{|c|}{ Non-high density lipoprotein cholesterol } \\
\hline Q1 & 519 & $16(3.1)$ & 1.0 & 1.0 & 1.0 & 1.0 & 1.0 \\
\hline Q2 & 530 & 19 (3.6) & $1.2(0.6-2.3)$ & $12(0.6-2.3)$ & $1.2(0.6-2.3)$ & $1.0(0.5-2.0)$ & $1.0(0.5-2.1)$ \\
\hline Q3 & 500 & $21(4.2)$ & $1.4(0.7-2.7)$ & $1.3(0.7-2.5)$ & $1.4(0.7-2.7)$ & $1.2(0.6-2.5)$ & $1.3(0.7-2.7)$ \\
\hline Q4 & 499 & $32(6.4)$ & $2.2(1.2-4.0)$ & $1.9(1.0-3.5)$ & $2.1(1.2-3.9)$ & $1.8(1.0-3.5)$ & $1.9(1.0-3.6)$ \\
\hline$P$ trend & & & 0.009 & 0.034 & 0.011 & 0.036 & 0.035 \\
\hline
\end{tabular}

OR, odds ratio; $\mathrm{Cl}$, confidence interval; unadj, unadjusted; aOR, adjusted odds ratio; Q, quartile.

Variables in † model A: first trimester BMl; ‡ model B: age, parity, smoking; § model C: age, parity, smoking, weight gain, placental weight, gestational diabetes; || model D: as $\mathrm{C}$ and in addition first trimester BMI. 
Table 4 Nested case control study. Clinical characteristics of non-diabetic/non-preeclamptic women with term macrosome babies ( $>4500 \mathrm{~g}$ ) compared with age-, parity-, and gestational age-matched non-diabetic/non-preeclamptic women with term normal weight babies $(3000-4000 \mathrm{~g})$. Results for age and weight parameters are expressed as means and S.D. Results for leptin and IGF-I are expressed as median (25-75 percentiles).

\begin{tabular}{|c|c|c|c|c|c|}
\hline \multirow[b]{2}{*}{ Age (years) } & \multicolumn{2}{|c|}{$\begin{array}{l}\text { Birth weight } \leq 4500 \mathrm{~g} \\
\quad(n=146)\end{array}$} & \multicolumn{2}{|c|}{$\begin{array}{l}\text { Birth weight }>4500 \mathrm{~g} \\
\quad(n=73)\end{array}$} & \multirow{2}{*}{$\frac{\boldsymbol{P} \text { value }}{0.97^{\star}}$} \\
\hline & 31.0 & 4.8 & 31.0 & 4.2 & \\
\hline Gestational age (weeks) & 40.6 & 1.0 & 40.6 & 1.0 & $0.90^{*}$ \\
\hline Birth weight (g) & 3573 & 278 & 4730 & 200 & $<0.001^{*}$ \\
\hline BML $\left(\mathrm{kg} / \mathrm{m}^{2}\right)$ & 22.6 & 3.7 & 24.6 & 4.3 & 0.001 * \\
\hline Placenta weight (g) & 651.1 & 109.2 & 846.1 & 150.7 & $<0.001^{*}$ \\
\hline Weight gain $(\mathrm{kg})$ & 15.0 & 4.6 & 17.4 & 5.2 & $0.001^{*}$ \\
\hline Smoking & $n=39$ & $27.3 \%$ & $n=12$ & $16.4 \%$ & $0.07 \dagger$ \\
\hline Nullipara & $n=49$ & $34 \%$ & $n=25$ & $34 \%$ & $0.88 \dagger$ \\
\hline Male & $n=74$ & $51.4 \%$ & $n=56$ & $76.7 \%$ & $<0.001 \dagger$ \\
\hline Leptin (ng/ml) & \multirow{2}{*}{\multicolumn{2}{|c|}{$\begin{array}{c}16.0(9.3-22.9) \\
154.0(13.0-173.5)\end{array}$}} & \multirow{2}{*}{\multicolumn{2}{|c|}{$\begin{aligned} 20.2 & (13.2-28.1) \\
158.5 & (140.8-183.5)\end{aligned}$}} & $0.01 \ddagger$ \\
\hline IGF-I (ng/ml) & & & & & $0.12 \ddagger$ \\
\hline
\end{tabular}

*Student's $t$-test, †Chi-square test, ¥Mann-Whitney test.

fetal size independent of maternal BMI. The main finding was that circulating metabolic factors known to be associated with the metabolic syndrome (increased non-HDL-cholesterol, decreased HDL-cholesterol and increased insulin) were independent determinants of macrosomia.

The study was considered population based even though it was performed in a hospital setting. The reason is that the obstetric care in Oslo at the time of the study was based on the principle that each hospital took care of all deliveries in defined geographical areas. The study population has been described elsewhere (20). Briefly, biases due to socio-economic selection, transfer to other hospitals or moving are unlikely. The study population included, however, only Scandinavian speaking (Caucasian) women. Validity of the anthropometric and clinical data was ascertained by a review of each medical record.

All the women in the current study were non-fasting mainly because it was impracticable to obtain fasting blood samples from all the participants. However, by testing non-fasting samples we eliminated the possibility to assess an indicator of insulin sensitivity. Thus the effect of insulin sensitivity as an independent determinant of fetal macrosomia remains to be clarified in the current context. Non-fasting blood values may, however, better reflect the normal physiological state. However, a consequence of using non-fasting samples is larger variation in the values measured due to difficulties in standardization, thereby increasing the risk of type 2 errors. It is also possible that blood values may be predictive in fasting but not in non-fasting states but also vice versa. Serum levels of triglycerides, glucose and insulin are especially sensitive to prandial status (food intake). The blood parameters analyzed in the current study were selected because they are generally closely related to BMI and the metabolic syndrome. We found that triglycerides, glucose and insulin were all closely correlated to maternal BMI indicating also that in a non-fasting state these variables reflect differences in metabolism in pregnant women according to their BMI.

Gestational diabetes has generally been considered an independent predictor of high birth weight although not all reports are consistent when adjusting for maternal BMI (15-17). The discrepancies between the studies may reflect differences in the prevalence of type II diabetes in the background population and variation in screening practices, diagnostic criteria and treatment modalities. In the present study, the effect of gestational diabetes on high birth weight after adjustment for BMI did not reach statistical significance. We cannot exclude a certain effect of gestational diabetes in the present population because after adjustment the odds ratio (95\% confidence interval) was 2.4 $(0.8-7.2)$. However, the main message to be taken from the majority of the studies performed is, in our opinion, that on a population basis high maternal BMI is a more important determinant of large size at birth than gestational diabetes.

Serum insulin was apparently an independent predictor of high birth weight (Table 3). However, insulin may be an effect modifier because among low BMI women insulin was higher for those delivering high birth weight babies. For those with high BMI there was no difference in the levels of insulin. Thus it may be questioned if adjustment for BMI is justifiable. To the extent that high serum insulin reflects reduced insulin sensitivity our finding indicates that slim women with insulin resistance are at increased risk of having a baby of large size. Interestingly, none of these women had gestational diabetes. On a population basis, slim women with high serum insulin do not, however, contribute markedly to the prevalence of macrosomic newborns. Our finding does, however, show that maternal insulin levels may, under given 
metabolic conditions, be independently involved in fetal growth.

In the current study, the serum glucose level was only a borderline, independent, risk factor of having a macrosomic infant. The relation between glucose and maternal BMI in relation to the size of the baby showed a similar trend as for insulin. This finding supports our notion (see above) that slim women with large babies may have decreased insulin sensitivity.

A high triglyceride level was not an independent risk factor for macrosomia in our study. We are not aware of previous studies where maternal serum insulin and triglyceride levels before 20 weeks of gestation have been related to birth weight. Later in pregnancy (24-28 weeks of gestation), however, triglyceride levels have been found to be independently correlated to birth weight, even after adjustment for maternal BMI (18). Similarly, obese women with macrosomic infants had higher serum triglyceride levels late in pregnancy than those without macrosomia (27). Thus, maternal triglyceride levels may be a significant determinant of fetal size in late but not in early pregnancy.

Serum leptin was, as expected, related to maternal BMI but not to the size of the baby after adjustment for BMI. This finding is in accordance with previous reports (28). This does not exclude the possibility that leptin may be an important mediator of the obesityinduced fetal macrosomia. Maternal serum levels of IGF-I have previously been shown not to be directly related to birth weight (29). IGF-I was, however, included in the present study because it is related to maternal weight and because we specifically wanted to study the risk of delivering a baby with weight in the upper percentiles (28). Not even with the design of the current study did we find any relation between maternal IGF-I in the first half of pregnancy and the risk of a large sized infant.

Schaefer-Graf et al. reported that pre-pregnancy obesity (BMI > 30) and a previous history of macrosomia were the only early predictors of large-for-gestational age infants among women with impaired glucose tolerance in pregnancy (30). From gestational week 28 fasting glucose level was also an independent predictor. In accordance with the results of the present study, the authors put forward the notion that different risk factors for macrosomia are predominant at different gestational ages. In particular, constitutional factors as reflected by a high BMI seem to be early determinants of large babies, whereas more specific metabolic parameters such as glucose and triglyceride levels become more important in the last trimester.

Placental weight was correlated both to maternal BMI and to infant size in our study. This finding may indicate that part of the effect of the altered physiology underlying high maternal weight may be mediated by an effect on placental nutritional capacity.

Interestingly, triglycerides and non-HDL-cholesterol were correlated to placental weight. It is therefore poss- ible that the metabolic changes associated with maternal overweight may promote placental growth.

The mechanisms underlying the strong association between maternal BMI and other anthropometric parameters and birth weight of the offspring remain elusive. A better insight into these mechanisms is needed especially given the increasing rate of newborns of large size in many countries (12). The short term (perinatal and obstetrical) risks of overweight mothers and fetuses are well documented $(11,24,31)$. More obscure are the long term effects on the health of the next generation. There is, however, increasing evidence that fetal over-nutrition (like under-nutrition) may have adverse effects on health of the next generation (32) This is clearly illustrated by the data indicating that exposure to a diabetic state in utero, apparently independent of genetic factors, increases the risk of obesity and diabetes in the next generation $(33,34)$. As pointed out by Catalano, a vicious cycle may be established with profound consequences for the health of future generations (7). This perspective is strengthened by the growing insight into the role of nutritional factors in epigenetic regulation of genes during fetal development (35).

In conclusion, the present prospective study of a normal population of 2050 term deliveries showed that blood parameters generally related to maternal overweight and metabolic syndrome were independently associated with the risk of having large sized newborns, even when adjustment was made for maternal body mass index. High maternal insulin levels among slim but not overweight women were predictive of macrosomic infants. The current evidence indicates that the biological mechanisms causing the relationship between maternal overweight and large sized infants involve a complex interaction between hormonal, placental and metabolic factors that may act differently at different stages of pregnancy.

\section{Acknowledgements}

We thank the following sources of support: the ThroneHolst Foundation, University of Oslo, Thematic Group Program, Aktieselskapet Freia Chocolade Fabrik's Medisinske Fond, Major og advokat Eivind Eckboes Legater, Familien Blix' fond til fremme av medisinsk forskning.

\section{References}

1 Spellacy WN, Miller S, Winegar A \& Peterson PQ. Macrosomia maternal characteristics and infant complications. Obstetrics and Gynecology 198566 158-161.

2 Jander C \& Lyrenas S. Third and fourth degree perineal tears. Predictor factors in a referral hospital. Acta Obstetrica et Gynecologica Scandinavica 200180 229-234.

3 Mocanu EV, Greene RA, Byrne BM \& Turner MJ. Obstetric and neonatal outcome of babies weighing more than $4.5 \mathrm{~kg}$ : an 
analysis by parity. European Journal of Obstetrics, Gynecology and Reproductive Biology 000092 229-233.

4 Curhan GC, Chertow GM, Willett WC, Spiegelman D, Coldditz GA, Manson JE, Speizer FE \& Stampfer MJ. Birth weight and adult hypertension and obesity in women. Circulation 199694 1310-1315.

5 Ahlegren M, Sørensen T, Wohlfart J, Haflidottir A, Holst C \& Melby M. Birth weight and risk of breast cancer in a cohort of 106504 women. International Journal of Cancer 2003 107 997-1000.

6 Sandhu MS, Luben R, Day NE \& Khaw KT. Self-reported birth weight and subsequent risk of colorectal cancer. Cancer Epidemiology Biomarkers and Prevention $200211935-938$.

7 Catalano PM. Obesity and pregnancy - the propagation of a vicious cycle? Journal of Clinical Endocrinology and Metabolism 200388 3505-3506.

8 Samaras TT, Elrick H \& Storms LH. Birthweight, rapid growth, cancer, and longevity: a review. Journal of the National Medical 200395 1170-1183.

9 Rosenberg TJ, Garbers S, Chavkin W \& Chiasson MA. Prepregnancy weight and adverse perinatal outcomes in an ethnically diverse population. Obstetrics and Gynecology $20031021022-1027$.

10 Jensen DM, Damm P, Sorensen B, Molsted-Pedersen L, Westergaard JG, Ovesen P \& Beck-Nielsen H. Pregnancy outcome and prepregnancy body mass index in 2459 glucose-tolerant Danish women. American Journal of Obstetrics and Gynecology 2003189 239-244.

11 Baeten JM, Bukusi EA \& Lambe M. Pregnancy complications and outcomes among overweight and obese nulliparous women. American Journal of Public Health 200191 436-440.

12 Johnson JW, Longmate JA \& Frentzen B. Excessive maternal weight and pregnancy outcome. American Journal of Obstetrics and Gynecology 1992167 353-370.

13 Kramer S, Morin I, Yang H, Platt RW, Usher R, McNamara H, Joseph KS \& Wu Wen S. Why are babies getting bigger? Temporal trends in fetal growth and its determinants. Journal of Pediatrics $2002141538-542$.

14 Flier JS. Obesity wars: molecular progress confronts an expanding epidemic. Cell $2004116337-350$.

15 Langer O. Fetal macrosomia: etiological factors. Clinical Obstetrics and Gynecology 200043 283-297.

16 Dang K, Homko C \& Reece EA. Factors associated with fetal macrosomia in offspring of gestational diabetic women. Journal of Maternal-Fetal Medicine 20009 114-117.

17 Okun N, Verma A, Mitchell BF \& Flowerdew G. Relative importance of maternal constitutional factors and glucose intolerance of pregnancy in development of newborn macrosomia. Journal of Maternal-Fetal Medicine 19976 285-290.

18 Kitajima M, Satoshi Oka S, Yasuhi I, Fukuda M, Rii Y \& Ishimaru T. Maternal serum triglycerides at 24-32 weeks' gestation and newborn weight in non-diabetic women with positive diabetic screens. Obstetrics and Gynecology 200197 776-780.

19 Verhaeghe J, Pintiaux A, Van Herck E, Hennen G, Foidart JM, Igout A \& Placental GH. IGF-I, IGF-binding protein-1, and leptin during a glucose challenge test in pregnant women: relation with maternal body weight, glucose tolerance, and birth weight. Journal of Clinical Endocrinology and Metabolism $2002872875-2882$.

20 Clausen T, Djurovic S \& Henriksen T. Dyslipidemia in early second trimester is mainly a feature of women with early onset preeclampsia. British Journal of Obstetrics and Gynaecology 2001 108 1081- 1087.

21 Skjaerven R, Gjessing HK \& Bakketeig LS. Birthweight by gestational age in Norway. Acta Obstetrica et Gynecologica Scandinavica $200079440-449$.

22 Le CT \& Lindgren BL. Computational implementation of the conditional logistic regression model in the analysis of epidemiologic matched studies. Computational Biomedical Research 1988 21 48-52.

23 Neggers Y, Goldenberg RL, Cliver SP, Hoffman MA \& Cutter GR. The relationship between maternal and neonatal anthropometric measurements in term newborns. Obstetrics and Gynecology 1995 $85192-196$.

24 Sebire NJ, Jolly M, Harris JP, Wadsworth J, Joffe M, Beard RW, Regan L \& Robinson S. Maternal and prepregnancy outcome: a study of 287213 pregnancies in London. International Journal of Obesity and Related Metabolic Disorders 200125 1175-1182.

25 Bergman RL, Richter R, Bergman KE, Plagemann A, Brauer M \& Dudenhausen JW. Secular trends in neonatal macrosomia in Berlin: influences of potential determinants. Paediatric Perinatology and Epidemiology 200417 244-249.

26 Ørskau J, Henriksen TB, Kesmodel U \& Secher NJ. Maternal characteristics of lifestyle factors and risk of delivering high birth weight infants. Obstetrics and Gynecology 2003102 115-120.

27 Merzouk H, Meghelli-Bouchenak M, Loukidi B, Prost J \& Belleville J. Impaired serum lipids and lipoproteins in fetal macrosomia related to maternal obesity. Biology of the Neonate 200077 17-24.

28 Henson M \& Castacane D. Leptin in pregnancy. Biology of Reproduction 200063 1219-1228.

29 Wiznitzer A, Reece EA, Homko C, Furman B, Mazor M \& Levy J. Insulin-like growth factors, their binding proteins, and fetal macrosomia in offspring of nondiabetic pregnant women. American Journal of Perinatology 199815 23-28.

30 Schaefer-Graf UM, Kjos SL, Kilavuz O, Plagemann A, Brauer M, Dudenhausen JW \& Vetter K. Determinants of fetal growth at different periods of pregnancies complicated by gestational diabetes mellitus or impaired glucose tolerance. Diabetes Care 2003 26 193-198.

31 Berkus MD, Conway D \& Langer O. The large fetus. Clinical Obstetrics and Gynecology $1999 \mathbf{4 2} 766-784$.

32 Catalano PM, Kirwan JP, Haugel-de-Mouzon S \& King J. Gestational diabetes and insulin resistance: role in short and long term implications for mother and fetus. Journal of Nutrition 20031331674 S-1683S.

33 Dabelea D, Hanson RL, Lindsay RS, Pettitt DJ, Impraatore G, Gabir MM, Roumain J, Bennett PH \& Knowler WC. Intrauterine exposure to diabetes conveys risks for type 2 diabetes and obesity. Diabetes $2000492208-2211$.

34 Dabelea D \& Pettitt DJ. Intrauterine diabetic environment confers risks for type 2 diabetes mellitus and obesity in the offspring, in addition to genetic susceptibility. Journal of Pediatric Endocrinology and Metabolism 2001 14 1085-1091.

35 Kaput J \& Rodriguez RL. Nutritional genomics: the next frontier in postgenomic era. Physiological Genomics 200416 166-177.

Received 15 June 2005

Accepted 1 September 2005 